This item was submitted to Loughborough's Research Repository by the author.

Items in Figshare are protected by copyright, with all rights reserved, unless otherwise indicated.

\title{
Creating the right 'vibe': emotional labour and musical performance in the recording studio
}

PLEASE CITE THE PUBLISHED VERSION

http://dx.doi.org/10.1068/a45619

\section{PUBLISHER}

(c) The Author. Published by Sage

\section{VERSION}

AM (Accepted Manuscript)

\section{PUBLISHER STATEMENT}

This work is made available according to the conditions of the Creative Commons Attribution-NonCommercialNoDerivatives 4.0 International (CC BY-NC-ND 4.0) licence. Full details of this licence are available at: https://creativecommons.org/licenses/by-nc-nd/4.0/

\section{LICENCE}

CC BY-NC-ND 4.0

\section{REPOSITORY RECORD}

Watson, Allan, and Jenna Ward. 2019. "Creating the Right 'vibe': Emotional Labour and Musical Performance in the Recording Studio". figshare. https://hdl.handle.net/2134/21404. 


\title{
Creating the right 'vibe': emotional labour and musical performance in the recording studio
}

\author{
Allan Watson* \\ Department of Geography, Science Centre, Staffordshire University, Leek Road, Stoke-on- \\ Trent, Staffordshire, ST4 2DF, UK \\ a.watson@staffs.ac.uk
}

Jenna Ward

Leicester Business School, De Montfort University, The Gateway, Leicester, LE1 9BH, UK jeward@dmu.ac.uk

*Corresponding author

Word count (including references): 8,722 including abstract and references 


\title{
Creating the right 'vibe': emotional labour and musical performance in the recording studio
}

\begin{abstract}
Recording studios are distinctive spaces in which artists are encouraged to expose their emotional selves in intimate moments of musical creativity and performance. In this paper, we focus on how music producers and recording engineers perform emotional labour as part of the 'performative engineering' of this musical creativity and performance. Through emotional labour performances, producers and engineers create recording studios as emotional spaces, characterised by trust and tolerance. This is often referred to, by recording studio staff and musicians, as creating the right 'vibe'. We highlight two forms of emotional labour as particularly pertinent to 'creating the right vibe': emotional neutrality and empathetic emotional labour. Emotional labour performances help to re-construct the recording studio as a space free of the social and feeling rules that otherwise shape our emotional landscape, and allow musicians to produce their desired musical performance.
\end{abstract}

Key words: emotional labour, creativity, recording studio, music production, music performance, emotional space 


\section{Introduction}

In this paper, we focus on how music producers and recording engineers perform emotional labour (Hochschild, 1983) as part of the 'performative engineering' of musical creativity and performance in the recording studio. It is well understood that the technical and creative talent of producers and engineers is crucial to the performance of the recording studio in terms of operating technical equipment and fostering artistic creativity. As 'technologists' (Horning, 2004), they are required to capture the performance of musicians in the studio and use their in-depth knowledge of technical equipment to edit and mould the captured sounds to create a musical recording. But the focus on the role as technologicallybased serves to marginalise a key aspect of studio work, namely the emotional support and encouragement required to facilitate the creative process (Leyshon, 2009). Our focus in this paper is on the way in which producers and engineers 'engineer' the performance of musicians both technically and performatively. We see this as the ability to elicit a performance from a musician that is full of 'authentic' emotion (Meier, 2011) and will therefore have an emotive impact on the listener in their everyday lives (see for example Juslin \& Laukka, 2004).

Specifically, we point to two forms of emotional labour producers and engineers use to regulate their own emotions and the emotions of artists to facilitate the creative process: empathetic emotional labour (Korczynski, 2003) and emotional neutrality (Ward \& McMurray, 2011; Smith \& Kleinman, 1989). This management of emotions is often referred to, by producers and engineers, as creating the right 'vibe'. Focusing on these often marginalised aspects of studio work we argue that recording studios are emotional spaces central to which is the work of record producers and recording engineers, who actively look 
to create an environment free of the everyday social and feeling rules that otherwise shape our emotional landscape, allowing musicians to produce desired emotional performances.

We begin with a review of recent literature on emotional labour, highlighting in particular work being produced from within geography, and considering a number of new areas of conceptual development in the emotional labour thesis. This is followed by a brief outline of the methodology employed in the research. In the main discussion, we draw on empirical data from 19 semi-structured interviews with producers and engineers working in recording studios in London to outline the various aspects of emotional labour performed in the studio. Firstly, we consider how producers and engineers perform emotional labour as part of the 'performative engineering' of musical creativity and to elicit emotional musical performances. This is followed by a consideration of how producers and engineers work to create the right 'vibe' within the studio space by outlining the importance of the development of (1) trust, drawing a distinction between emotive trust and capacity trust (Ettlinger, 2003) and (2) tolerance of client behaviour, and in particular of alcohol consumption substance abuse. In concluding the paper, we argue that recording studios are emotional spaces in which producers and engineers regulate their own emotions by way of managing the emotions of musicians and recording artists as they perform music.

\section{Emotional labour}

'The Managed Heart' (Hochschild, 1983) introduced the concept of emotional labour. Hochschild (1983) argued that the development of the service sector had made a new kind of labour prominent in Western society. The flight attendants and bill collectors that she interviewed were exchanging what was once a private part of their selves for a wage. Their 
emotions and feelings had become organisational commodities. Emotional labour is defined by Hochschild as:

... the management of feeling to create a publicly observable facial and bodily display; emotional labour is sold for a wage and therefore has exchange-value... This labour requires one to induce or suppress feeling in order to sustain the outward countenance that produces the proper state of mind in others. (1983:7, emphasis in original)

Hochschild's conceptualisation of emotional labour recognises the importance of regulating emotions in accordance with "situational dictates" (Kruml \& Geddes, 2000:11) or what she termed 'feeling rules' (Hochschild, 1979), an extension of Ekman's (1973) display rules. Most of us know which emotions are appropriate at a given time due to social norms. We learn this complex system or 'rule book' of emotion regulation from a young age and through parental guidance. In a Durkeheimian sense, the ability to regulate our emotions facilitates social cohesion (Thoits, 1985). Emotional labour, then, requires an implicit knowledge of social norms, but in an organisational context these must be further combined with display (Ekman, 1973) and feeling rules (Hochschild, 1979). However, emotional labour is not only about the inducement or suppression of one's own emotions but also the ability to "produce the proper state of mind in others" (Hochschild, 1983:7). In other words, the ability to elicit appropriate emotional responses from others requires a performance in which your own emotions are managed.

Korczynski's (2003, 2009) distinction between empathetic and antipathetic emotion management (often emotional labour where performed for a wage) appreciates the 
complexity of these performances. Korczynski classifies empathetic emotional labour as that which is intended to produce a positive emotional state in others, such as the sense of happiness, safety or care that may be associated with the work of nurses or cabin crew. By contrast, antipathetic emotional labour, which is considerably less well understood arguably due to a lack of empirical focus (Ward \& McMurray, forthcoming), is intended to produce a negative emotional state in others, as in the fear and insecurity potentially employed by debt collectors, or prison guards. Emotional neutrality (Ward \& McMurray, 2011), however, disrupts the empathetic-antipathetic, or positive-negative dichotomy. Defined as a "technique used to suppress emotions felt whilst displaying unemotional behaviour, wherein the suppression of the emotion is the performance itself" (2011:1585), emotional neutrality speaks of the unspoken, and often un-heard, relational-based elements of what are commonly seen as task-based (Hewitt, 2006) or 'technical' (Horning, 2004) job roles.

Since its introduction emotional labour has been the focus of much empirical work in a number of academic disciplines including psychology, sociology, social-psychology, organisational behaviour and nursing. Research interests here bifurcated, between, on the one hand those focused on emotional labour as a feature of particular occupations, including for example flight attendants (Taylor \& Tyler, 2000; Williams, 2003); nurses (James, 1989; Bolton, 2000, 2005); beauty therapists (Sharma \& Black, 2001); paralegals (Lively, 2002); call-centre operators (Taylor, 1998; Shuler \& Sypher, 2000); adventure guides (Sharpe, 2005); Disneyland employees (Van Maaenen 1991) and bill collectors (Sutton, 1991) and on the other hand, research focused on emotions themselves and workers' attempts to manage them (see for example Grandey, 2000; Zapf, 2002; Dieffendorff \& Gosserand, 2003; Syed, 2008; and Payne, 2009). 
Over the course of a decade, geographers have become increasingly engaged with issues around emotion as part of a wider 'emotional turn' in a range of disciplines (see Anderson and Smith, 2001; Davidson and Milligan; 2004) and have explored emotional and affective labour in a variety of contexts. For example, Crang (1994) considers workplace geographies of display in restaurants; McDowell (2001) the emotional labour and masculinities in the financial service industries; Wellington and Bryson (2001) image consultancy and emotional labour; Bryson (2007) the 'distanciated' emotional labour associated with the off-shoring of corporate services; Askins (2009) emotion in academic activism; Huang and Yeoh (2007) emotional labour and transnational domestic work; Dyer et al. (2008) and Batnitzky and McDowell (2011) emotional labour/body work in caring labour in the UK's National Health Service; and Major (2009) the affective labour of nurses and hotel workers.

With more specific relation to this paper, there has been a growing interest in the geographies of music and emotion (see Wood and Smith, 2004; Wood et al., 2007). In particular, geographers have considered the emotional and bodily performances of musicians and audiences (see for example Holman Jones (1999) on women's music; Morton (2007) on Irish traditional music; and Duffy et al. (2011) on festival spaces). However, little has been written either on the emotional labour of others working in the music industry, or on recording studios as distinctive spaces of music making. One way of addressing this issue is "to find clues about the emotional content of social relations... from people whose professional lives are all about evoking emotion" (Anderson \& Smith, 2001: 7). We focus on music producers and recording engineers, working in recording studios, as one such group of people performing emotional labour, a component of which is the evocation of emotions in musical performance. Spaces of musical performance, such as recording studios, are 
particularly revealing for research into emotions given that they are spaces in which emotions are 'routinely heightened' (Anderson and Smith, 2001) and where "the emotional content of human relations is deliberately laid bare" (Wood and Smith, 2004: 535).

In order to fully understand the kinds of emotional labour that occur in recording studios, it is necessary to understand the musical dimensions of these spaces. Small's (1998) account of 'musicking is helpful here, in which he argues that there is no such thing as music, but rather practices of musicking. Central to the concept of musicking is understanding music as practice and performance - a 'doing' of music. As Wood et al. assert, "Music making is a material practice: it is embodied and technologised; it is staged; it takes place" (2007: 869). Furthermore, for Small, the act of musicking establishes in the place where it is happening a set of relationships, between the people who are taking part in the performance. Musical performance is therefore understood as "an encounter between human beings that place through the medium of sounds organised in specific ways" (1998: 10).

\section{Methodology}

Between June 2010 and March 2011, a total of 19 interviews were undertaken with individual recording studio producers and engineers working in recording studios in London. All but two of the interviews were undertaken at the recording studios in which the interviewees worked. With the exception of a small number of large recording facilities, the studios in which interviews were conducted were relatively small project facilities (many single-room). None of the studios were in buildings originally constructed with this particular use in mind, but rather buildings or sections of buildings that had been converted for the purpose. The majority of the studios occupied part of a building also occupied by a range of 
other uses, including office blocks, 'cultural' centres, industrial premises and warehouses. Two of the smallest studios were located in converted brick buildings in residential gardens.

Pseudonyms are used in this paper to protect the anonymity of the interviewees. All 19 interviewees were men aged between 20-65 years of age. We see this as being representative of music production, recording and engineering remaining almost exclusively male forms of employment. They had a range of educational backgrounds through which they had learnt the required skills for sound engineering. Some had completed University qualifications in sound engineering and/or music; others had no formal sound-engineering qualifications but rather had learnt their skills within the work environment of the studio, having begun their careers as runners and tape operatives and then working their way up through the hierarchical studio structure to become engineers and/or producers.

The interviews resulted in over 18 hours of recorded data. The interviews posed a range of questions relating to creative work in the studio, including creative collaboration between musicians and recording studio staff; the role of technology in the creative process; social networks and social capital; and the politics of work. While no questions were posed specifically to interrogate performances of emotional labour, emotion was a strong emergent theme across the interviews. In analysing the data using a thematic analysis, and in subsequently writing this paper, we came to recognise that emotions and feelings are "messy matters to work with" and "even trickier to "write up" (Bondi \& Davidson, 2011: 595). Adequately representing the emotional qualities of studio work and musical performance in written words is a difficult task, and one which we approach with care. 


\section{Technical and performative engineering}

Recording studios are considered spaces in which "appropriate and available technologies are assembled and hired to musicians and producers for periods of time, for the purpose of sound recording" (Gibson, 2005: 196). They are (relatively) insulated spaces that give musicians, producers and engineers the required conditions in which to experiment and create music, and which are privileged to the most intimate moments of musical creativity and emotive performance (Watson et al., 2009). These 'moments' of creativity and performance are produced not by the musician alone, but through relations between musicians, producers, engineers, and recording technologies (Gibson, 2005). In this sense, producers and engineers could be considered cultural intermediaries, on whom the ability of musicians to make music is dependent (Hennion, 1989; Shuker, 1994; Pinch and Bijsterveld, 2004). Accordingly, studios can be considered 'sociotechnical spaces' (Leyshon, 2009) and 'machinic complexes' (Gibson, 2005), that is to say they are spaces of collaborative relationships, housing assemblages and encounters of bodies and technologies.

The work of recording engineers and producers represents the point where music and modern technology meet. Kealy (1990) describes the complex set of technical abilities and tacit knowledge required to make sense of this intersection. These include knowing the characteristics of hundreds of microphones and a variety of acoustic environments, and how to employ them to best record a musical instrument; the capabilities and applications of a large array of sound-processing devices; the physical capacities of recording media (such as tapes and discs) for accepting and reproducing sounds; the operation of various recording machines; and how to balance or 'mix' the analogue or digital signals coming from a variety 
of live and pre-recorded sound sources, to produce a recording that is "a recognizable and effective musical experience" (Kealy, 1990: 208).

Producers and engineers must simultaneously perform their role as 'technologists' (Horning, 2004) in a highly competent manner whilst also making aesthetic judgements (Kealy, 1990). A tension thus exists between the artistic performance of music and the technical practice of capturing that sound (Middleton, 1990). This is outlined by Barry, the house engineer of a large recording studio in North London:

... on some of the smaller projects you are producing and engineering at the same time, which is really hard because you have to split your head into two different worlds at the same time. So one side is doing a very technical job and thinking about cables and computer editing, and the other side is going "oh, hang on a minute, is this the right tempo?", or "is the song in the right key?", or "how can I make that section work better?"... so that's quite difficult.

The technology-art dualism is, we argue, better described as a 'triumviri' of technology-art-performativity. Nervousness, tension, and a lack of confidence in musicians and recording artists when faced with recording in a formal studio space can often be prohibitive to artists producing a desired performance or a 'good take'. Joseph, a male producer-engineer and studio owner, noted that often "it just takes one sentence to transform everybody's performance" and that providing this input is a big part of being a producer or engineer. Encouragement and support is especially important for those musicians and recording artists who are entering the studio environment for the first time, as noted by Tim, an engineer-producer and owner of a small project studio in South London: 
A lot of people go "oh $\mathrm{f}^{* *}$ king hell, I'm in a studio" and so... as a producer you have got to be supportive, you have got to see them through it. Just kind of hold their hand through it sometimes really and just be there for them. And they appreciate that. At the end of the day they come away feeling good about the session...

This type of performative labour involves the ability to build personal relationships and accordingly manage emotions in a way that is conducive to completing a particular task. The recording studio therefore not just a place of technical practice; it is a space in which relationships are built and maintained, often over a short but very intense period of work. Thus studio work highlights a particular form of creative labour that emphasises the relational nature of working rather than the task-based aspect of work per se (see Steinberg and Figart, 1999; Hewitt, 2006; Ward \& McMurray, 2011). The importance of the relational elements of studio work are attested to by John, a producer-engineer working at a major recording studio:

...the art of it is really people-based. So getting a good sound and all that stuff ends up being five per cent of your job. Ninety five per cent is people... It is probably more people based than it is technical... you have obviously got to deliver on the technical but it's not really the essence of the job.

As recent work on the geographies of emotions has shown, issues of relationality are inseparable from emotions (see Thien, 2005). Thus, while in defining the term 'emotional labour' Hochschild (1983) was considering service work in its widest context, the concept of emotional labour is particularly applicable to work in the recording studio. We can hear this in Alan's (a mastering engineer working in a major studio in North London) emotive testament below: 
I get an enormous amount of pleasure working with people if they know what they want. I get furious with rage if I'm working with people who are fussy and pernickety for the sake of it... people like yesterday, they came in [and] they were a bloody nightmare, and they kept pitching in. And you have to be professional and pleasant and nice to them, but at the end of the day I was in an absolute rage.

There is a direct admission of emotion regulation here, despite being angry and frustrated, the engineer purposively suppressed his real feelings in order to behave in a 'professional' manner. However, the dispassionate neutrality that is often associated with professionalism (Smith \& Kleinman, 1989) was not the only element to this performance. Not only did he describe himself as being professional but also 'pleasant and nice', Korczynski (2003) would label this empathetic emotional labour in order to induce a positive emotional experience for the clients. In the same sense Andy, a producer-engineer and owner of a small project studio in Soho, speaks of 'diplomacy' as a key part of the emotional offering:

...you have to be as diplomatic as possible and do some ego massaging often, and make sure that everyone is comfortable. It always comes down to what the client wants.

The idea that it "always comes down to what the client wants" is representative of the management of emotions in return for a wage, and demonstrates the extent to which the performance, communication, and display of emotions are central to studio work. As such, studio work cannot be conceptualised as solely an economic or technical performance. This is somewhat at odds with the laboratory-like status of recording studios in the early 20th century, in which employees were considered technical specialists required to wear white coats at all times (Leyshon, 2009). 


\section{Emotional performances}

\section{"Music is the shorthand of emotion" Tolstoy}

In studio work, there are interactive effects between the work context, the work content, and the emotional state of the individual (Ashforth and Humphrey, 1993). Here the work content refers to the particular music recording project and the genre of music being recorded, while the work context refers to the studio space and the relationships between studio workers and clients. However, it is important not to romanticize the realities of recording. Studio environments are often small enclosed spaces, the pressure of undertaking a recording project with often tight time constraints often means that recording is

... quite an intense process... you are all basically in a small room together for 18 to 20 hours doing this thing and living it. You basically live with these people for a really intense period of time sleeping very little, working in a really focused kind of environment...

(Brian, engineer)

Within these 'intense' work contexts producers and engineers are privileged to the most intimate moments of emotive performance. As Wood et al. (2007) note, musical performances are about intimate encounters and the sharing of an emotional experience with other people involved in the performance. The importance accorded to shared experience supports those conceptions of emotion and affect that privilege proximity and intimacy (see Pile, 2010). In many instances, songs, and in particular, lyrics will be loaded with feeling and emotion drawn from particular emotional experiences of musicians and recording artists. Sensitivity and empathy towards these emotional performances is therefore imperative. As England and Farkas (1986) assert, emotional labour involves "efforts made to understand 
others, to have empathy with their situation, to feel their feelings as part of one's own" (pg. 91). One interviewee noted the need to be very sensitive when suggesting any alterations to songs, particularly when it comes to suggesting changes to lyrics. Another interviewee, Terry, a resident engineer at a medium-sized studio in North-West London, also noted the need to be very sensitive in such situations:

...it is a very exposing experience for a lot of artists to come into the studio and say here's a song I've written because they trust you to not turn around and say it's crap, your voice sounds terrible, your lyrics are awful and you've just told me the whole story about your failed love life and I'm going to rip the $\mathrm{p}^{*}$ ss out of you about it.

Through emotive performances, producers and engineers are exposed to the personal emotions of the recording artist. John explained how, because projects contain a lot of personal material from the recording artist, "sometimes you do get brought into their personal lives". He then goes on to say "but that's part of the job." As Richard, a recording engineer at a large studio in Shoreditch explained, in order to get a believable and emotive performance from a recording artist, particularly with vocal performances, it is often necessary to get them into a particular emotional state:

... when you are trying to capture a good vocal take you need to believe that they are saying what they are saying. It needs to be believable. So you really need to put them in a position where, if they are singing a sad song, they have been dumped by their boyfriend, something like that, you have got to put them in that position, get them in that frame of mind.

As such, an important part of work in the recording studio is the ability to perform emotional labour in such a way as to affect the client; to move them emotionally, for them to be 
possessed by emotion (see Simonsen, 2007). Parallels can be drawn here with Grindstaff's (2002) and Hesmondhalgh and Baker's (2008) accounts of television workers being required to elicit the strongest possible version of the emotions felt by contestants on confessional talk shows and talent shows respectively. Studio producers and engineers must elicit strong emotions from the musician or recording artists to capture the most emotive performance possible.

The management of emotional responses is a key part of the work that takes place within these 'creative industries'. Recording producers/engineers are, then, evokers of and witnesses to emotional displays that in most other work-based contexts, and even social contexts, would be considered inappropriate. Telling the confessional tale of a relationship that ended badly to someone whom you have only met that morning, and recounting it in such a way as to evoke their empathy (or in other words to move them) would not be congruent with social norms outside of the recording studio. In this sense, producers and engineers attempt to re-define the display rules (Ekman, 1973) and feeling rules (Hochschild, 1979) within the studio in a bid to facilitate powerful, emotional performances. They frequently referred to this as 'creating the right vibe'.

\section{Creating the right 'vibe'}

Music performance in the recording studio takes place in a very particular physical setting. As a physical acoustic and technological space, the materiality of the studio is clearly very important to the 'sound' of the music being produced (Leyshon, 2009) and to the 'vibe' created; as Wood et al. argue, "what can be worked through, practised, performed is shaped in important ways by the materiality of musical spaces" (2007: 870). However, it is also 
important to recognise the studio as a relational space - not only a physical setting, but also a social setting which determines the meanings being generated by the performance. The recording studio is a space of musicking (Small, 1998) in which the intimate, emotional quality of human relations is laid bare (see Wood and Smith, 2004).

In this sense, the atmosphere that producers and engineers work to create is important, because performing under certain circumstances generates different meanings from performing them under others (Small, 1998). Performing in a recording studio is for example very different from performing in front of a live audience, and this generates different meanings from a performance. In a live setting, the audience are active participants in the musical performance, feeding energy (or failing to feed energy) back to the performers as the performance takes place (Small, 1998). Often, live performance involves spontaneous and experimental elements which the audience respond to; see for example Gibson (1999) on rave music; Cooper (2004) on Jamaican dancehall culture; and Fraser and Ettlinger (2008) on drum and bass music.

Inside the studio, performances are also often 'live' in the sense that they involve spontaneity and speculation, improvisation or mistakes that that only happen as they are being played in the 'now' of the performance (Morton, 2005). Producers and engineers look to capture a 'definitive' version of these performances 'on record'. However, unlike in truly live performance settings, studio performances occur without an audience present. In this regard, the emotional labour performed by producers and engineers in creating the right 'vibe' becomes in part about feeding energy to the performer in the absence of an audience. Bringing energy and emotional performance to a recording studio is crucial as listeners who will buy a recording will not be part of a 'live' performance; rather because they will use the 
recordings to create their own event, it becomes necessary for musicians and producers/engineers to create performances on record that will serve the purposes of these contexts (Small, 1998).

Creating a relaxed atmosphere, conducive to the process of creating and performing was a common theme, most often referred to as creating the right 'vibe':

...the whole vibe of it all...it's getting everybody relaxed and into it...if a client feels happy and comfortable they are more likely to be creative aren't they?

(Anthony, producer, West London)

This 'vibe' is considered to be a combination of both a relaxed atmosphere and an open and creative relationship between the producer/engineer and artist, thereby making the process of recording enjoyable, and encouraging musicians and recording artists to give their 'best' performance. We contend that 'creating the right vibe' requires producers and engineers to manage their own emotions and the emotions of artists and musicians through performances of trust and tolerance. It is to these that we attend in the following two sections.

\section{Trust}

An essential part of putting clients at ease and building relationships that allow for creative collaboration in the recording studio is the development of trust. Trust can be understood as an "interpersonal phenomenon" (Ettlinger, 2003: 146) and "a sociospatial process enacted by agents through relations" (Murphy, 2006: 429), shaped by, amongst other things, knowledge, emotions, reputation, and appearance. As Banks et al. (2000) assert new 
ties of trust, whether they be strong or weak, are an important part of the creative process, leading to collaboration and new cultural products. It is important from the offset that trust is very quickly developed in the relationship between the producer/engineer and the musician or recording artist.

More specifically, following Ettlinger (2003: 146) we can identify two types of trust; emotive trust "based on one's personal feelings about others"; and capacity trust "based on one's judgements about another's capacity for competent performance in a workplace”. For Ettlinger (2003), capacity trust is often predicated on emotive trust. A critical part of developing emotive trust inside the recording studio is that studio workers 'locate' their clients in terms of a range of cultural categories (Crang, 1994) and adjust their own performance to suit each situation. How engineers and producers communicate a specific social identity can foster feelings that facilitate the emergence of trusting sentiments (Murphy, 2006). Jack, an engineer from a major recording studio, noted:

The moment I meet them [a client] ... I have got to try and work [them] out, understand them, read all their body signals, read what they are re up to, what they are thinking about... From the moment I meet them I am having to get their trust straight away.

And Bill, an experienced engineer-producer and owner of a small project studio in North London, echoed:

...if you can somehow get their trust, that's what production is about. It's totally about having the artist's confidence and trust in you. If you can do that quickly, then it saves a lot of time. 
Given that trust is rooted in experience with an individual (Christopherson, 2002), and that the development of trust involves a range of cognitive, emotive and communicative factors (Murphy, 2006), engineers and producers have to actively work to develop and sustain relationships of trust with their clients. This is something Giddens (1994) terms 'active trust'. Building strong bonds of trust is particularly important within the creative space of the recording studio, given the unique nature of the work that takes place within it.

However, building trust and creating the right vibe is not always easy. Hesmondhalgh and Baker (2008) see trust and emotional labour caught in a destructive relationship.

The pressure to deliver work that will help build one's reputation impacts on the individual's ability to do emotional labour. Yet building one's reputation hinges upon the management of emotions (Hesmondhalgh and Baker 2008:113)

This 'impact' is perhaps best described as acute in the case of the music industry where the use of illegal drugs and excessive alcohol consumption can lead to emotionally heightened experiences including destructive behaviours, conflict and tensions, all of which require careful handling and negotiation from recording engineers and producers to maintain a good reputation, maintain trust and ensure a high quality recording outcome.

\section{Tolerance}

A key part of creating the right 'vibe' is the producers and engineer's emotional performance, projecting a relaxed and friendly disposition, which might often contradict their own feelings. Ben, an experienced producer and owner of a medium-sized studio in Notting 
Hill, explained how getting the best performance from a musician or recording artist is not about forcing a performance by putting people under pressure; rather, it is about creating a relaxed atmosphere and teasing out a performance, often by being relaxed and easy-going and putting tense and nervous clients at ease:

Sometimes once that red light goes on people do tend to tense up a bit so getting the best performance isn't about going out there and throwing tea cups at the wall like Alex Ferguson ... You've really got to the get the atmosphere right and get everybody relaxed... sometimes it happens and sometimes it doesn't.

The relaxed disposition of studio workers and their encouragement of the creative process must also extend to the uses, and often abuses, of the recording space. Perhaps an unintended consequence of the re-definition of social norms, display and feeling rules is the artist's treatment of studio staff. As John explained:

...if someone's being a d*ck you have to let them if there's time pressures and you've got to get them to do their performance. You've got to get over the fact that they're calling you an $a^{*}$ se hole or they're being a pain... you still have to do your job in that fixed timescale so you do it.

Thus an important part of emotional labour is dealing with negative or abusive behaviour from clients when this occurs. Here, emotional labour is important in regulating interaction and obviating interpersonal problems (Ashforth and Humphrey, 1993); however getting over the fact that someone is being abusive towards you as an individual is no doubt easier said than done. An important emotional implication of studio work is thus the suppression of anger and frustration on the part of the studio worker in the name of good working relations 
with clients, and often the producer or engineer will attempt to placate the musician or recording artist. As James, a producer-engineer and owner of a small studio in North London noted:

...if you're an engineer in a studio and you erase over the wrong performance, you'll know about it very, very quickly. And I'm quite often trying to say to clients, 'Actually, we're making music. We're not solving the Middle East peace crisis. We're just trying to make music here.

The non-reaction to this kind of abuse maybe in and of itself a performance of 'emotional neutrality' (Ward \& McMurray, 2011; Smith \& Kleinman, 1999).Outside of the space of the recording studio, in which the social norms have been re-defined, this kind of behaviour would not be met with calm professionalism. As Grindstaff (2002:132) so eloquently describes, eliciting emotional performances requires "either pretending to care ... or trying not to care too much".

Often, relaxing artists and fostering the required creative atmosphere requires studio workers to have a liberal attitude towards, or at least a tolerance of, the consumption of alcohol and use of illegal drugs inside the space of the studio. A number of the interviewees suggested that the musicians or recording artists have a couple of drinks to relax before recording was common place and 'not a problem'. Luke, a producer-engineer running his own medium-size studio in Fulham, West London, explains his own attitude to the use of the studio space and studio equipment: 
Ideally people don't spill beer on the desk and stuff but generally it's like, there are no rules and regulations as such in this space. You know, feel free to do what you want and things are there to be used. You know, microphone, drop it, I am not going to freak out about it.

The music industry has a reputation for the high level availability and use of illegal drugs, taken to enhance the creativity of talented musical performers (see for example Shapiro, 2003; Raeburn et al., 2003; and Miller and Quigley, 2011 on substance use among musicians across a range of musical genres; and also Singer and Mirhej, 2006, on the role played by illicit drugs in the evolution of Jazz music in the United States). This popular image is often born out within the space of the studio as these quotes testify:

"I've seen that table covered in coke, do you know what I mean? ... I was working with one artist and she turned up and she had a bottle of Jack Daniels and she'd drunk three quarters of it..."

(Anthony, West London)

"He had taken a few too many drugs and has ripped the tape off the tape machine."

(Jack, North London)

The prolific link between the music industry and drug and alcohol (ab)use is one that also raises some interesting questions for the emotional nature of the work that takes place within the creative space of the recording studio. Tolerance of alcohol and drug use is a way to create the right 'vibe'; yet there are perhaps associated limits to which their use is helpful to the creative process. Bill recalled his experience of working with a famous guitar band in the early 1990s who had spent the majority of the recording project "getting off their faces... taking a lot of drugs where there's serious work to be done". Yet, as Anthony noted from his 
own experience, "it's just amazing that you can do that many drugs and actually come out with something at the end of it". Recording producers and engineers interviewed had come to accept the use of drugs and alcohol within the space of the recording studio which is arguably demonstrative of the way in which the recording studio as a 'sociotechnical space' (Leyshon, 2009) has its own social rules and norms that may be conducive to creating the right vibe. Perhaps as a consequence producers and engineers have become adept at tolerating behaviours and emotions (either positive or negative) of artists when they are under the influence of drugs and alcohol by managing their own emotions, specifically through performances of emotional neutrality (Ward \& McMurray, 2011).

\section{Conclusion: emotional labour in the recording studio}

The recording studio, as with any other space of musical performance, is constituted by a wide range of different emotional relations. As Wood and Smith describe:

There are, of course, many types of performance event inhabiting, indeed defining, many kinds of performance spaces. The emotional relations which constitute these also come in all shapes and sizes. They include fear, anger, frustration, yearning, hate and hurt; they embrace well-being, contentment, hope and happiness. (2004: 535)

Musical performance is a setting in which the emotional is routinely heightened (Anderson \& Smith, 2001), that is to say the emotions associated with performance are often felt very intensely. Recording studios are unique spaces of music performance, in the sense that the emotions of performances and relations are experienced in a very insulated space, often under conditions of intense collaboration. Thus recording studios are more than simply physical and 
technological spaces for music-making; they are relational and emotional spaces which determine the meanings generated by musical performance.

This study describes the emotional and relational work that take place within the space of the recording studio. Testimonies of this private, enclosed and often 'secret' world of the recording studio have identified at least some of the approaches and techniques used to evoke powerful, emotional and creative performances. We have highlighted how producers and engineers actively induce or suppress their own emotions in order to manage the emotions of the artists and musicians, using emotional neutrality and empathy to develop trust, tolerate drug and alcohol use, and re-define social norms, feeling and display rules. The recording studio thus becomes an emotional space, characterised by trust and tolerance, and free of the social and feeling rules that otherwise shape our emotional landscape, allowing musicians to produce a desired emotional musical performance. This space is actively created by producers and engineers, through their performance of emotional labour. Producers and engineers are then not just 'technologists' (Horning, 2004) recording the performance, but also provide the emotional support and encouragement required to facilitate the creative process (Leyshon, 2009). The absence of a 'live' audience to feed energy to the often spontaneous and speculative musical performances that take place in the studio lends the emotional labour of producers and engineers an added importance in feeding energy to, and providing feedback on, musical performance in the studio.

The findings presented in this paper build on research into the emotional performances of musicians and audiences (see Holman Jones, 1999; Morton, 2007; Duffy et al., 2011) by highlighting the importance of emotions to the work of others involved in the production of music, and by emphasising the need to understand the musical dimensions of 
the spaces in which music-making occurs. This research has two key implications for geographical research more widely. Firstly, we suggest that there is a need to give greater consideration to the importance of emotions in various kinds of labour and performance across a range of industries and settings. In applying the concept of emotional labour to creative work in the recording studio, for example, we have revealed that while this labour in many ways mirrors the types of emotion management found in service industries, it also involves the active elicitation of particular emotions as part of musical performance. Secondly, and related to the above, we argue that to understand how and why emotional labour is performed in particular ways, one must understand the complex nature of the contexts and spaces in which it occurs; as material spaces (and often technical spaces), as spaces of emotion and performance constituted by social and emotional relations, as relational time-spaces actively made and re-made by the practices of those working within them (see Simonsen, 2007; also Anderson and Harrison, 2006).

\section{Acknowledgements}

The authors would like to thank three anonymous reviewers for their constructive and insightful comments, which have helped us to bring the discussion presented in this paper into sharper focus. We are extremely grateful to the producers and engineers who so kindly and generously gave their time to take part in interviews. Allan Watson would like to thank Phil Hubbard and Michael Hoyler for their advice during the early stages of the research.

\section{References}


Anderson, B, Harrison, P, 2006, “Questioning affect and emotion” Area 38(3) 333-335

Anderson K, Smith S J, 2001, "Editorial: emotional geographies" Transactions of the Institute of British Geographers 26 7-10

Ashforth B E, Humphrey R H, 1993, "Emotional labour in service roles: the influence of identity" The Academy of Management Review 18(1) 88-115

Askins, K, 2009, "That's just what I do: placing emotion in academic activism" Emotion, Space and Society 2(1) 4-13

Banks M, Lovatt A, O'Connor J, Raffo C, 2000, "Risk and trust in the cultural industries" Geoforum 31 453-464

Batnitzky A, McDowell L, 2011, "Migration, nursing, institutional discrimination and emotional/affective labour: ethnicity and labour stratification in the UK National Health Service Social \& Cultural Geography 12(2) 181-201

Bolton S C, 2000, "Who cares? Offering emotion work as a 'gift' in the nursing labour process" Journal of Advanced Nursing 32 580-586

Bolton S C, 2005, Emotion Management in the Workplace (Palgrave Macmillan, Basingstoke)

Bondi, L, Davidson, J, 2011, "Lost in translation" Transactions of the institute of British Geographers 36(4) 595-598

Bryson J R, 2007, “The 'second' global shift: the offshoring or global sourcing of corporate services and the rise of distanciated emotional labour" Geografiska Annaler B 89(1) $31-43$

Christopherson S, 2002, "Project work in context: regulatory change and the new geography of media" Environment and Planning A 34 2003-2015

Cooper C, 2004, Sound Clash: Jamaican Dancehall Culture at Large (Palgrave Macmillan, New York, NY) 
Crang P, 1994, "It's showtime: on the workplace geographies of display in a restaurant in Southeast England" Environment and Planning D 12 675-704

Davidson J, Milligan C, 2004, "Embodying emotion sensing space: introducing emotional geographies" Social \& Cultural Geography 5(4) 523-532

Dieffendorff J M, Gosserand R H, 2003, "Understanding the emotional labour process: a control theory perspective" Journal of Organizational Behaviour 24 945-959

Duffy M, Waitt G, Gorman-Murray A, Gibson C, 2011, "Bodily rhythms: corporeal capacities to engage with festival spaces" Emotion, Space and Society 4(1) 17-24

Dyer S, McDowell L, Batnitzky A, 2008, "Emotional labour/body work: the caring labours of migrants in the UK's National Health Service” Geoforum 39 2030-2038

Ekman P, (1973) Cross culture studies of facial expressions. In Ekman P (ed.) Darwin and facial expressions: A century of research in review (Academic Press, New York)

England P, Farkas G, 1986, Households, Employment, and Gender: A Social, Economic and Demographic View (Aldine, New York)

Ettlinger N, 2003, “Cultural economic geography and a relational and microspace approach to trusts, rationalities, networks and change in collaborative workplaces" Journal of Economic Geography 3(2) 145-171

Fraser A and Ettlinger N, 2008, "Fragile empowerment: the dynamic cultural economy of British drum and bass music" Geoforum 39(5) 1647-1656

Gibson C, 1999, "Subversive sites: rave culture, spatial politics and the internet in Sydney, Australia" Area 31(1) 9-33

Gibson C, 2005, "Recording studios: relational spaces of creativity and the city" Built Environment 31(3) 192-207 
Giddens A, (1994) "Replies and critiques" in Beck U, Giddens A, Lash S (eds.) Reflexive Modernisation; Politics, Tradition, and Aesthetics in the Modern Social Order (Polity Press, Cambridge)

Grandey A A, 2000, "Emotion regulation in the workplace: a new way to conceptualise emotional labour" Journal of Occupational Health Psychology 5 95-110

Grindstaff L, 2002, The Money Shot: Trash, Class, and the Making of TV Talk Shows. (University of Chicago Press, Chicago)

Hardt M, Negri, A, 2001, Empire (Harvard University Press, London)

Hennion A, 1989, “An intermediary between production and consumption: the producer of popular music" Science, Technology, and Human Values 14(4) 400-424

Hesmondhalgh D, Baker S, 2008, "Creative work and emotional labour in the television industry" Theory, Culture and Society 25 (7-8) 97-118

Hester E, 2002, In-Flight Entertainment (Ebury Press, London)

Hewitt H, 2006, Front desk talk: A study of interaction between receptionist and patients in general practice surgeries (University of Edinburgh, Edinburgh)

Hochschild A R, 1979, "Emotion work, feeling rules, and social structure" The American Journal of Sociology 85 551-575

Hochschild A, 1983, The Managed Heart: Commercialisation of Human Feeling (University of California Press, Berkeley)

Holman Jones S, 1999, "Women, musics, bodies, and texts: the gesture of women's music" Text and Performance Quarterly 19(3) 217-235

Horning S S, 2004, "Engineering the performance: recording engineers, tacit knowledge and the art of controlling sound" Social Studies of Science 34 (5) 703-731 
James N, 1989, "Emotional labour: skill and work in the social regulation of feelings" Sociological Review 37 (1) 15-42

Juslin, P N, Laukka, P, 2004, "Expression, perception and induction of musical emotions: a review and questionnaire study of everyday listening" Journal of New Music Research 33 (3) 217-238

Kealy E, 1990, "From craft to art: the case of sound mixers and popular music" In Frith S, Goodwin, A (eds.) On Record: Rock, Pop and the Written Word. (Routledge, London) $207-220$

Korczynski M, 2003, "Communities of coping: collective emotional labour in service work" Organization, 10(1) 55-79

Korczynski M, 2009, “The Mystery Customer: Continuing Absences in the Sociology of Service Work” Sociology 43 952-967

Korczynski M, \& Ott, U, 2004, "When production and consumption meet: cultural contradictions and the enchanting myth of consumer sovereignty" Journal of Management Studies 41 575-599

Kruml S M, Geddes D, 2000, "Exploring the dimensions of emotional labour: The heart of Hochschild's work" Management Communication Quarterly 14(1) 8-49

Leyshon A, 2009, "The software slump?: digital music, the democratization of technology, and the decline of the recording studio sector within the musical Economy" Environment And Planning A 41 1309-1331

Lively J K, 2002, "Client contact and emotional labor: Upsetting the balance and evening the field" Work and Occupations 29 198-225

Longhurst B, 1995, Popular Music and Society (Polity Press, Cambridge) 
Major C, 2008, “Affect work and infected bodies: biosecurity in an age of emerging infectious diseases" Environment and Planning A 40 1633-1646

McDowell L, 2001, "Men, management and multiple masculinities in organisations" Geoforum 32(2) 181-198

Meier L M, 2011, "Promotional ubiquitous musics: recording artists, brands and "rendering authenticity” Popular Music and Society 34(4) 399-415

Middleton, R, 1990, Studying Popular Music (Open University Press, Buckingham)

Miller K E, Quigley B M, 2011, “Sensation-seeking, performance genres and substance use among musicians" Psychology of Music 39(3) 1-22

Morton, F, 2005, "Performing ethnography: Irish traditional music sessions and the new methodological spaces" Social \& Cultural Geography 6(5) 661-676

Munro I, 2012, "The management of circulations: biopolitical variations after Foucault" International Journal of Management Reviews 14(3) 345-362

Murphy J T, 2006, "Building trust in economic spaces" Progress in Human Geography 30 (4) $427-450$

Negus, K, 1992, Producing Pop: Culture and Conflict in the Popular Music Industry (Edward Arnold, London)

Negus K, 1999, Music Genres and Corporate Cultures (Routledge, London)

Payne J, 2009, "Emotional labour and skill: A reappraisal" Gender, Work and Organization 16 (3) 348-367

Pinch T, Bijsterveld K, 2004, "Sound studies: new technologies and music" Social Studies of Science 34 (5) 635-648

Raeburn S D, Hipple J, Delaney W, Chesky, K, 2003, “Surveying popular musicians' health status using convenience samples" Medical Problems of Performing Artists 18 113119 
Shapiro H, 2003, Waiting for the Man: The Story of Drugs and Popular Music (Helter Skelter Publishing, London)

Sharma U, Black P, 2001, "Look good, feel better: Beauty therapy as emotional labour" Sociology 34 913-931

Sharpe E K, 2005, "Going above and beyond": The emotional labor of adventure guides" Journal of Leisure Research 37 29-50

Shuler S, Sypher, B D, 2000, "Seeking emotional labour: when managing the heart enhances the work experience" Management Communication Quarterly 14(1) 50-89

Shuker R, 1994, Understanding popular music (Routledge, London)

Simonsen, K, 2007, "Practice, spatiality and embodied emotions: an outline of a geography of practice” Human Affairs 17 168-181

Singer M, Mirhej, G, 2006, "High notes: the role of drugs in the making of Jazz" Journal of Ethnicity in Substance Abuse 5 (4) 1-38

Small C, 1998, Musicking: The Meanings of Performing and Listening (Wesleyan University Press, London)

Smith A C, Kleinman S, 1989, "Managing emotions in medical school: Students' contact with the living and the dead" Social Psychology Quarterly 52(1) 56-69

Steinberg R J, Figart D M, 1999, "Emotional labour since: the managed heart" The Annals of the American Academy of Political and Social Science 561 (8) 8-26

Sutton R I, 1991, "Maintaining norms about expressed emotions: The case of bill collectors" Administrative Science Quarterly 36 245-268

Syed J, 2008, "From transgression to suppression: Implications of moral values and societal norms on emotional labour" Gender, Work \& Organization 15(2) 182-201

Tankel J D, 1990, "The practice of recording music: remixing as recording" Journal of Communication 40 (3) 34-46 
Taylor S, 1998, "Emotional labour and the new workplace" in Thompson P, Warhurst C (eds.) Workplaces of the Future (Macmillan, London)

Taylor S, Tyler M, 2000, "Emotional labour and sexual difference in the airline industry" Work, Employment and Society 14 (1) 77-95

Thien, D, 2005, "After of beyond feeling? A consideration of affect and emotion in geography" Area 37(4) 450-456

Thoits P A, 1985, "Self-labelling processes in mental illness: The role of emotional deviance" The American Journal of Sociology 91 221-249

Tyler M, Abbott P, 1998, "Chocs away: weight watching in the contemporary airline industry" Sociology 32 (3) 433-450

Van Maanen J, 1991, Tales of the Field (University of Chicago Press, Chicago)

Ward J, McMurray, R, 2011, "The unspoken work of GP receptionists" Social Science and Medicine 72 (10) 1583-1587

Watson A, Hoyler M, Mager C, 2009, "Spaces and networks of musical creativity in the city" Geography Compass 3(2) 856-878

Wellington, C A, Bryson, J R, 2001 “At face value? Image consultancy, emotional labour and professional work" Sociology 35(4) 933-946

Williams C, 2003, "Sky service: The demands of emotional labour in the airline industry" Gender, Work and Organization 10 513-550

Wood N, Smith, S J, 2004, "Instrumental routes to emotional geographies" Social \& Cultural Geography 5(4) 533-548

Wood N, Duffy M, Smith S J, 2007, "The art of doing (geographies of) music" Environment and Planning D: Society and Space 25 867-889

Huang S, Yeoh, B S A, 2007, "Emotional labour and transnational domestic work: the moving geographies of 'maid abuse' in Singapore” Mobilities 2(2) 195-217 
Zapf D, 2002, "Emotion work and psychological well-being: A review of the literature and some conceptual considerations" Human Resource Management Review 12 237-268 